\title{
Establish Protocol for Attention of patient Care to Promote Physical Status of Patient with Cerebral infarction
}

Abeer Yahia Mahdy*

Medical-Surgical Nursing department, faculty of nursing, Njran University

*Corresponding Author

Abeer Yahia Mahdy

\section{Article History}

Received: 29.08 .2019

Accepted: 06.09.2019

Published: 30.09 .2019

\begin{abstract}
Nowa days was common health problem. It is the 3rd cause of death after heart disease and cancer. Serious long-term disability caused by this status. The current study aimed to establish Protocol for Attention of Nursing care to promote physical stuats of Patient with cerebral infarction at King Khalid Hospital (KKH). A convenience sample of 60 patients who had cerebral infarction and able to communicate in the departments of medical, surgical units at KKH. Over a period of 7 months were recruited. One tool were used to collect data it is Interview qutionnair sheet developed to assess patient personal data, patient physical statusand and educational requirement the first part was questionnaire sheets to estimate personal data, second part was to assess patient physical and educational requirment. Results of this study concluded that, the majority of the studied subject's physical status were dependent in them selves to performing daily living activities, and did not have adequate knowledge about cerebral infarction. Conclutios: about half of the studied subjects were dependent in performing of daily living activities, more than half of studied subjects were had unsatisfactory knowledge but improved post protocol.The relations between sociodemographic data, physical status, there was statistical significant relation between patient emographic data and physical status. The study recommended that Facing the patient physical status by Help the patients to perform the daily living activitie perform In-service Training for patient and relative to discuss the effect of $\mathrm{Cl}$ on physical status of the patients, National strategies are highly required to support patients with $\mathrm{Cl}$ and their caregivers and Further research is needed to study the rehabilitation and discharge programs that would help the patient with $\mathrm{Cl}$ to adapt with their physical disabilities
\end{abstract}

Keywords: Cerebral infarction, patient care, physical status

\section{INTRODUCTION}

Acute cerebral infarction $\mathrm{Cl}$ is a most common cerebrovascular disease with high disability and fatality rates, which is an important and difficult point in clinical treatme, Nakashima, etal( 2016) [24] . Cerebrovascular infarction (Cl) is the primary cerebrovascular disorder in the United Status. it is a sudden loss functioning of brain resulting from interruption of the blood supply to any part of the brain. Marianne, 2016 [16]. Cerebral infarction is a term used to describe neurological changes caused by an interruption in the blood supply to a part of the brain. Ischemic stroke is caused by thrombotic or embolic clots that obstruct the blood flow to the brain. Hemorrhagic transformation $(\mathrm{HT})$, which refers to a spectrum of ischemia-related brain hemorrhage, is a frequent spontaneous complication of ischemic stroke, Sussman ES, Connolly ES [1].

$\mathrm{Cl}$ is one of the most frequent causes of hospitalizations and mortality rate in Brazil, resulting in some kind of impairment (partial or complete) in most patients. In 2009, 160,621 hospital admittances due to cerebrovascular diseases were recorded, with a mortality rate of 51.8 per each group of 100,000 inhabitants .Almeida,2012 [21].

(Hemorrhagic transformation (HT) is a frequent complication of acute ischemic stroke that is especially common after thrombolytic therapy Zahng J, et al. [2]. Neuronal death occurs after 6 minutes of oxygen deprivation. Following neuronal death, permanent disabilities usually ensue as neuronal replication is not possible [3]. Risk factors for stroke are non-modifiable that can't be changed as age, race, gender, and heredity. Modifiable risk factors may be pathologic disorders as Diabetes, hypertension, heart disease, current smoking, and long-term heavy alcohol consumption are major risk factors for stroke in young adults. Given that the majority of these factors are either correctable or modifiable, prevention strategies may have the potential to reduce the impact of stroke in this age group and hypotension migraine headaches, conditions that increase risk of blood clotting e.g. sickle cell anemia, life style factors as excessive alcohol consumption, cigarette smoking, obesity, high fatty diet, and drug abuse [4].

Copyright @ 2019: This is an open-access article distributed under the terms of the Creative Commons Attribution license which permits unrestricted use, distribution, and reproduction in any medium for non commercial use (NonCommercial, or CC-BY-NC) provided the original author and source are credited. 
Patient with cerebral strok about 15 million in the world. Every one of six people is high risk for stroke. About 6 millionperson die and about $10 \%$ of stroked patients die per year from complications before being discharged from hospitals [5]. The Physical Needs is important dimension to requiring attention to best care (El shamma, 2010).

In acute phase of cerebral vasculaer accident, should focus efforts on survival physical needs and prevention of complications. Nursing Care contiane continuing efficient neurologic assessment, support of respiratory, monitoring of vital signs, careful positioning, management of gastero intestinal problems, monitoring of fluide \& electrolyte, and nutritional status. So the care shoude focus on impaired physical mobility due to Limitation in independent, purposeful physical movement of the body or of one or more extremities. (Matt, 2013).

\section{Significance of the Study}

During training in the medical-surgical departments the researcher, observe that the patient with cerebral infarction had many problems affect cure. The main problem is patient dependency in case of impaired physical staus. Also deficet of patient knowledge. In addition, many studies concerned with this researche items becouse it is the second main cause of death worldwide affecting people over the last decades. Ana etal 2016[22]

\section{Aim of the Study}

Establish Protocol for Attention of patient Care to Promote Physical Status of Patient with Cerebral infarction

\section{Research hypothesis}

- $\quad$ Cl will affect patient dependency

- $\quad$ Their will be relation between Patient demographic data and patient with $\mathrm{Cl}$ physical status

- $\quad$ educational needs about physical status of Patient with $\mathrm{Cl}$ will be improved after establish protocol

\section{SubJeCtS ANd Methods}

\section{Research design}

A quasi-experimental design was utilized to achieve the aims of this study.

\section{Setting}

Current study was conducted in medical surgical units at King Khalid Hospital (KKH). These departments were selected data in cause of reasonable and representative numbers from the patients with $\mathrm{Cl}$ in the previous mentioned settings.

\section{Subjects}

A convenience sample included 60 patients with cerebrovascular infarction $\mathrm{Cl}$ from mentioned units at $\mathrm{KKH}$ their age ranged from 18 years old and less than 55 years, and able to communicate.

\section{Research Tools for Data Collection \\ Data were collected by using one tool:}

Interview qutionnair sheet, to assess patient personal data and patient educational need regarding to physical status. It divided in to two parts. Part 1) patient personal data: developed by the researchers. Included; (age, sex, marital status, level of education, and working).

Part2) patient phsical assessment sheet. To assess physical status.and patient dependancy Barthel index scale [7] this scale was translated into Arabic languge by [6].This Arabic version was used in the present study. The scale consists of 10 questions, which assess the person's abilities in the areas of feeding, moving (from wheelchair to bed and return), personal toilet, getting on and off toilet, and others.

\section{Scoring System}

The total score of the scale is (20) points. It ranged from0-7=dependent, from 8-12=independent with assistant, and from 13$20=$ independent in daily living activities performance.

\section{Ethical considerations}

Ethical Considerations: Informed the patients and relative about the purpose and benefits of the study, inform them that their participation was voluntary, and they have the right to refuse to participate in the study without giving any reason. In addition, confidentiality and anonymity of the subjects were assured through coding of all data. Insuring that the study not harming but useful for them, concent was taken from participants in the study, after explaintion the aim of the study.

\section{Pilot study}

A pilot study was carried out on 6 patients with $\mathrm{Cl}$ from previous mentioned units. They were not excluded from the total subjects. It was done to evaluate the reliability and the applicability of tools and estimate the proper time required for answering the questionnaire, the tools not modified according to the result of pilot study. 


\section{Procedure (Field Work and data collection)}

- Researcher obtained permission from hospital director of the mentioned hospital to conduct the study. An oral consent was taken from the patients and their nurses in order to participate in research process. To obtain their approval for conducting the study after explaining its purpose.

The researchers reviewed current related literature and theoretical knowledge of the various aspects that concerning topic of the study to develop and construct the study tools of data collection. Moreover, planning for prtocole of patient care education. Translating tool into Arabic language to be clear understand.

The tools validity: The tools of the study were tested for face and content validity by panel of experts consisted of five experts from medical-surgical departments at Faculties of Nursing. Based on their comments.

The tools reliability: The tools were tested and measured by Cronbach's Alpha test. The value was 0.789 for patient' physicalstatus and knowledge questionnaire, the value was 0.859 for nurses' observational checklist, and the value was 0.796 for nurses' productivity Detected patient needs which transformed to development of patient care protocole; it was developed based on determined needs of studied patients and relevant review of the literature. It was aiming to prepare and developed. It covers the following contents; activity and rest, physical mobility, walking, and general activity of daily living.

The prtocole were ".30m to 1 hours for each patient alone; Protocole achieved by using available resources, relevant contents, and instructional strategies for each patient. Different methods of teaching were used like; discussion, and brainstorming. Instructional media included; Power point presentation for knowledge, video about care and emphasize with booklet. After that Feedback at the end

\section{The implementation phase}

The researcher met subjects and explained the aim and nature of the study and method of filling the questionnaires. This was done individually or with relative.

Interview questionnaires filled by the researchers before implementing. After that strat the evaluation

The evaluation phase:

The data were collected immediately after implementation of the designed protocol by using the previous designed tools by using the previous designed tools to evaluate the effect of protocol

\section{StATISTICAL AnALYSIS}

Data were verified prior to computerized entry using the statistical package for social science (SPSS) programme to analyz data. It was also expressed as frequency and percentage and probability of errors ( $p$-value) test was used to examine the relation between qualitative variables. A statistically significant difference was considered at $\mathrm{p}$-value $\mathrm{p} \leq 0.05$, and a highly statistically significant difference was considered at $\mathrm{p}$-value $\mathrm{p} \leq 0.01$.

\section{RESULTS}

Table-1: Distribution of the Studied Subjects According to their Socio-demographic Characteristics $(n=60)$

\begin{tabular}{|l|c|c|}
\hline \multicolumn{1}{|c|}{ Items } & N & $\%$ \\
\hline Age: & & \\
18:28 & 0 & 0.0 \\
28-38 & 0 & 0.0 \\
38:58 & 60 & 100.0 \\
\hline Sex : & 26 & \\
Male & 34 & 43.3 \\
Female & & 56.7 \\
\hline Marital status: & 0 & \\
Single & 44 & 0.0 \\
Married & 16 & 73.3 \\
Divorced & 0 & 26.6 \\
Widowed & & 0.0 \\
\hline Educational level: & 30 & \\
Illiterate & 20 & 50.0 \\
Read and write & 4 & 33.3 \\
Secondary & 6 & .067 \\
Universal & & 1.0 \\
\hline job / occupation: & 55 & \\
Working & 5 & 91.7 \\
Not working & & 8.3 \\
\hline
\end{tabular}

Table (1) showed that, $100 \%$ of studied subjects' their age with in 38 years old to above, $(56.7 \%)$ were female, $(73.3 \%)$ were married, (50\%) were illiterate, and (91.7\%) were working. 
Table-2: The degree of dependency in daily living activities (Physical status) in the studied subjects

\begin{tabular}{|l|c|c|}
\hline $\begin{array}{l}\text { Degree of physical status } \\
\text { (dependency) }\end{array}$ & Number & Percent \\
\hline Dependent on them self & 31 & $56 \%$ \\
\hline need assistant & 20 & $33.3 \%$ \\
\hline Independent on other & 9 & $15 \%$ \\
\hline
\end{tabular}

Table (2) showed that $(56 \%)$ of subjects were dependent on others, $(33.3 \%)$ were need to assistance, and $(15 \%)$ were Independent in the performance of daily living activities.

Table-3: Relation between soicodemographic data of cerebral infarction patient and their physical status ( $N=60)$

\begin{tabular}{|c|c|c|c|c|c|c|c|c|}
\hline \multirow{3}{*}{ Sociodemographic data } & \multicolumn{8}{|c|}{ Physical status } \\
\hline & \multicolumn{2}{|c|}{$\begin{array}{c}\text { In } \\
\text { dependent }\end{array}$} & \multicolumn{2}{|c|}{$\begin{array}{c}\text { Need to } \\
\text { assistance }\end{array}$} & \multicolumn{2}{|c|}{ Dependent } & \multirow[t]{2}{*}{$\mathrm{X}^{2}$} & \multirow[t]{2}{*}{$\mathbf{P}$} \\
\hline & $\mathrm{N}$ & $\%$ & $\mathrm{~N}$ & $\%$ & $\mathrm{~N}$ & $\%$ & & \\
\hline $\begin{array}{l}\text { Age } \\
\geq 35\end{array}$ & 29 & 48.3 & 4 & 6.7 & 27 & 45.0 & - & - \\
\hline $\begin{array}{l}\text { Sex } \\
\text { Male }\end{array}$ & 11 & 40.7 & 1 & 3.7 & 15 & 55.6 & & \\
\hline Female & 18 & 54.5 & 3 & 9.1 & 12 & 36.4 & $\begin{array}{c}2.4 \\
4\end{array}$ & $\begin{array}{c}>0.0 \\
5\end{array}$ \\
\hline $\begin{array}{l}\text { Marital status } \\
\text { Single }\end{array}$ & 0 & 0.0 & 0 & 0.0 & 0 & 0.0 & & \\
\hline Married & 18 & 40.0 & 3 & 6.7 & 24 & 53.3 & 5.6 & $>0.0$ \\
\hline Divorced & 10 & 71.4 & 1 & 7.1 & 3 & 21.4 & 8 & 5 \\
\hline Widowed & 1 & 100.0 & 0 & 0.0 & 0 & 0.0 & & \\
\hline $\begin{array}{l}\text { Educational level } \\
\text { Illiterate }\end{array}$ & 22 & 57.9 & 2 & 5.3 & 14 & 36.8 & & \\
\hline Read and write & 7 & 43.75 & 1 & 6.25 & 8 & 50.0 & 16. & $<0.0$ \\
\hline secondary & 0 & 0.0 & 1 & 25.0 & 3 & 75.0 & 60 & 5 \\
\hline Universal & 0 & 0.0 & 0 & 0.0 & 2 & 100.0 & & \\
\hline job / occupation & & & & & & & & \\
\hline Working & 19 & 54.3 & 4 & 11.4 & 12 & 34.3 & 5.6 & $>0.0$ \\
\hline Not working & 10 & 40.0 & 0 & 0.0 & 15 & 60.0 & 1 & 5 \\
\hline
\end{tabular}

Table (4) Distribution of the studied subjects according to their total knowledge related to cerebral infarction knowledge educational need.

\begin{tabular}{|l|c|c|c|c|}
\hline Items & \multicolumn{2}{|c|}{ Pre protocol } & \multicolumn{2}{c|}{ Post protocol } \\
\hline $\begin{array}{l}\text { Educational needs and } \\
\text { concerns }\end{array}$ & $\mathbf{N}$ & \% & $\mathbf{N}$ & $\%$ \\
\hline Un satisfactory knowledge & 40 & 66.7 & 11 & 18.3 \\
\hline Average knowledge & 15 & 25.0 & 15 & 25.0 \\
\hline Satisfactory knowledge & 5 & 8.3 & 34 & 56.7 \\
\hline
\end{tabular}

Table (4) Showed that (66.7\%) from the studied subjects had unsatisfactory knowledge about cerebral infarction knowledge pre protocol but after protocol it become $18.3 \%$ and pre protocol $8.3 \%$ had satisfactory knowledge and increase to 56.7 after protocol

\section{Discussion}

As regarding to demographic data, the present study portrayed that the patient age of all studied subjects more than 38 years old and above. This is may be due to this age is high risk group because some disease as as diabetes and hypertension and bad life style. These finding were similar to the study done by Elshafi [8] studied the stroke patients needs and concern Feigin [9], who 
studied the stroke epidemiology in the developing countries he said that stroke is the disease of older adults because approximately $60 \%$ to $75 \%$ of all $\mathrm{Cl}$ occur in persons over 65 years of age.

The present study showed that the majority of the studied subjects were female group, and less than half were male. This in view of researcher may be due to hormonal physiological changes in this age, or use of contraceptives pill, stress and bad life style as decrease mobility and excerces. These findings were in agreement with Qureshi et al. [10] who studied the stroke frequencies of intracerebral bleeding, cerebral infraction and sub-arachnoid hemorrhage showed that, out of 100 cases there were 44 cases of the studied subjects were males and 56cases were females. Abed elmordy [11] studed home care for stroked patients. The results of the present study revealed that, the majority of the studied subjects were married, illiterate, working.

These findings were in agreement with the results done by El-shamaa et al. [11] who studied the assessment of Biopsychsocial needs for patients with chronic Cerebrovascular stroke, and revealed that the majority of the studied subjects were married, illiterate, and manual workers in (male group), and housewives in (female group) Elshafi [12].

As regarding of physical needs for patients with cerebrovascular infarction: current study showed that about half of the studied subjects were inaprpraite physical status and dependent in performing daily living activities this may be due to the affected brain centers and disabilities that appears from $\mathrm{Cl}$. About one quarter were independent with assistance, and the other quarter were independent in performing of daily living activities that may be due to this subjects were in recovery stage, and had low level from stroke.

Abd elhameed. [5] who studied the caregivers training and health status outcomes in cerebral stroke elder patients slightly agreed with me and found that about two thirds of the studied sample before implementation of the program were dependent in performing daily living activities, about one -third of the studied subjects were independent with assistance in performing daily living activities.

Regarding to assessment of the educational needs and concerns for patients with $\mathrm{Cl}$ this study showed that, more than half from the studied subjects were had unsatisfactory knowledge about stroke this may be due to the majority of the studied subjects NOT interested with $\mathrm{Cl}$, one quarter had average knowledge about $\mathrm{Cl}$, and less than one to tenth had satisfactory knowledge about $\mathrm{Cl}$.

This result as well as Hafsteinsdottir et al. [13] who emphasized that, the educational needs of patients with a stroke and their caregivers, reported that patients with $\mathrm{Cl}$ and caregivers reported many and diverse educational needs, which often were not met. Patients and caregivers wanted information that was tailored to their situation.

\section{The relation between soicodemographic data and patient physical status}

The present study showed that, there was statistical significant relation between educational level and physical status . There was a highly statistical significant relation between (occupation) and educational.

El shamaa et al. [11]. who studied the assessment of Biopsychsocial needs for patients with chronic Cerebrovascular stroke disagreed with me in, there was statistical significant relation between (occupation) and physical needs, there were no statistically significant relations between different sociodemographic data, Taylor anxiety scale, and depression scale, There was a statistically in significant relation between social dysfunction rating scale and gender.

Regarding to studied subjects according to their total knowledge related to cerebral infarction knowledge educational need, the present study portrayed that more than have of them had unsatisfactory knowledge about cerebral infarction knowledge pre protocol but after protocol it decreased and pre protocol smale number of subject had satisfactory knowledge and increase after protocol This finding is supported by (Kamel,2010), who said that the knowledge and practice during implementation program, such as work activities and group discussion, brainstorming, group activities, ... etc. findings was matched with(Mahfouz, 2011 ) [ 19]. , found that there was high statistical improvement in the level of knowledge after intervention of program. Also results in the line of (Mohammed 2014), who reported that there was significant improvement in knowledge after implementation of the educational program. Moreover, this consistent (Kirwa 2015) [18]. , who reported that the continuous practice of hand skills lead to improvement of knowledge and performance. The Guo, Z and Zhou, X( 2016) [23]. The level of serumb2-MG can evaluate the severity of disease, infarction size and the degree of in $\mathrm{l}$ lammation reaction in patients with acute cerebralinfarction

\section{CONCLUSION}

\section{The present study concluded that} not Married.

The studied subject's age were more than 35 years old, the majority of the studied subjects were female, married, illiterate, 
- $\quad$ The $\mathrm{Cl}$ patient physical status, about half of the studied subjects were dependent and about one quarter were independent with assistant in performing of daily living activities.

- Regarding to assessment of the educational requirment, more than half of studied subjects were had unsatisfactory knowledge and one quarter had average knowledge about $\mathrm{Cl}$ and improved post protocol.

- The relations between sociodemographic data, physical status, there was statistical significant relation between patient emographic data and physical status.

\section{RECOMMENDATIONS}

Based on the results and conclusions of the current study, the following recommendations are suggested

- $\quad$ Facing the patient physical status by Help the patients to perform the daily living activitie.

- In-service Training for patient and relative to discuss the effect of $\mathrm{Cl}$ on physical status of the patients

- National strategies are highly required to support patients with $\mathrm{Cl}$ and their caregivers.

- $\quad$ Further research is needed to study the rehabilitation and discharge programs that would help the patient with $\mathrm{Cl}$ to adapt with their physical disabilities,

\section{REFERENCES}

1. Patni, S., Flynn, P., Wynen, L. P., Seager, A. L., Morgan, G., White, J. O., \& Thornton, C. A. (2007). An introduction to Toll-like receptors and their possible role in the initiation of labour. BJOG: An International Journal of Obstetrics \& Gynaecology, 114(11), 1326-1334.

2. Yu, Y., Zhou, Y. B., Liu, H. C., Cao, S. G., Zahng, J., \& Wang, Z. H. (2013). Effects of preoperative oral carbohydrate on postoperative insulin resistance in radical gastrectomy patients. Zhonghua wai ke za zhi [Chinese journal of surgery], 51(8), 696700.

3. Gopez, J. (2012). Stroke Nursing Care Plan. Risk for Aspiration Retrieved on October 6, 2012. From the web: http:// rnspeak. Com/ nursing. care.plan /Stroke .nursing .care .plan .risk for aspiration.

4. Hopkins, J., \& Rao, V. (2012): Neuropsychiatry of Stroke, Retrieved on February 13, 2012. From the web: http: //www.Hopkins medicine. Org.

5. Abd elhameed, S., El shazly, S., Ali M., \& Ebrahim, H. (2010). Caregiver Training and Health Status Outcomes in General Stroke Elder Patients. Thesis for Doctoral Degree in Nursing Science, Geriatric Nursing, Faculty of Nursing, Mansaura University.

6. Hallaj, F. (2007). Activity Patterns of Residents in Elderly Homes. Unpublished Thesis, MSc, Alexandria: Faculty of Nursing, University of Alexandria, 2007.

7. Mahoney, F. I., \& Barthel, D. W. (1965). Functional evaluation: the Barthel Index: a simple index of independence useful in scoring improvement in the rehabilitation of the chronically ill. Maryland state medical journal.

8. El-Shafi, M. A., Gheith, E. M. S., El-Mohsen, A. A., \& Suleiman, H. S. (2014). Stability Analysis and Correlations among Different Stability Parameters for Grain Yield in Bread Wheat. Scientia, 6(3), 135-140.

9. Feigin, V. (2005).Stroke Epidemiology in the Developing world. Lancet, 2005; 365 (9478): 2160-1.

10. Qureshi, F., Bilal, A., Khan, R., \& Khalid, G.(2007).Stroke Frequencies of intracerebral bleed, cerebral infraction, and sub arachnoid hemorrhage, 14(4)580-585 in Faisalabad hospital(Asia).

11. El-shamaa, E., El-Banouby, M., \& Mustafa, N. (2010). Assessment of Biopsychsocial Needs for patients with Chronic Cerebrovascular Stroke. Thesis for Master Degree in Nursing Science, Medical-Surgical Nursing, Faculty of Nursing, Ain Shams university Egypt. Journal of pharmaceutical and biomedical sciences, 1(3)69-78.

12. El-Shafi, M. A., Gheith, E. M. S., El-Mohsen, A. A., \& Suleiman, H. S. (2014). Stability Analysis and Correlations among Different Stability Parameters for Grain Yield in Bread Wheat. Scientia, 6(3), 135-140.

13. Hafsteinsdottir, T., Vergunst, M., Lindeman, E., \& Schuurmans, M., (2010). Educational needs of patients with a stroke patient and their caregiver: a systematic review of the literature, Malasia, http: //www.ncbi .nlm. nih. gov /Pub med.

14. Matt Vera, BSN, R.N . 8+ Cerebrovascular Accident (Stroke) Nursing Care Plans

15. . -August 1, 201314

16. Marianne Belleza ,Cerebrovascular Accident (Stroke). R.N. -November 8, 2016

17. Kamel F.F., (2010): Study the effectiveness of teaching the clinical administrative course by using computer-based training in developing nurse intern administrative knowledge and skills at Benha University Hospital. Unpublished Doctorate Thesis, Faculty of Nursing, Benha University: 87.

18. Kirwa L., and Gakere Z., (2016): Clinical Competence of Nursing Students. Pp: 27. Available at:https://www. theseus.fi/bitstream/handle/10024/109754/Kirwa_Lilian. pdf?sequence=3. Accessed on July 2018.

19. Mahfouz H.H.E., (2011): Developing clinical teaching skills of the assisting teaching staff at Benha Faculty of Nursing, Unpublished Doctorate Thesis in Nursing Administration, Faculty of Nursing, Benha University, Pp: 93.

20. Mohammed N.A.A., (2014): The effect of time management educational program for newly baccalaureate graduate nurses on their productivity, Unpublished Doctorate Thesis in Nursing Administration, Faculty of Nursing, Benha University, Pp: 1-5 \& 108. 
21. Almeida SRM. Análise epidemiológica do Acidente Vascular Cerebral no Brasil. Rev Neurocienc [Internet] 2012[cited 2015 Apr 22]:20(4):481-2

Available from:

http://www.revistaneurociencias.com.br/edicoes/2012 RN2004/editorial\%2020\%2004/edSara.pdf [ Links ]

22. Ana $C$, Maria A, Aurilene $L$,Islene $V$,Débora $B$,Karine, Mônica. Nursing diagnoses in patients with cerebral vascular accident: an Rev. Bras. Enferm. vol.69 no.4 Brasília jul./ago. 2016. http://dx.doi.org/10.1590/0034-7167.2016690423i

23. Guo, Z and Zhou, X( 2016) .Correlation between the condition of patients with acute cerebral infarction and serumb2 microglobulin levels, Contents lists available atScienceDirectJournal of Acute Diseasejournal homepage:www.jadweb.orgJournal of Acute Disease2016; 5(4): 281-2852812221-6189/Copyright @ 2016 Hainan Medical College. Production and hosting by Elsevier B.V. This is an open access article under the CC BY-NC-ND license (http://creativecommons.org/licenses/by-nc-nd/4.0/).

24. Nakashima T, Noguchi T, Haruta S, Yamamoto Y, Oshima S,Nakao K, et al. Prognostic impact of spontaneous coronary arterydissection in young female patients with acute myocardial infarc-tion: a report from the angina pectoris-myocardial infarctionmulticenter investigators in Japan.Int J Cardiol2016;207: 341-8 